\title{
Test, Analysis and Evaluation of R2100 Distance Sensor used for Robot Grass Cutting
}

\author{
ChunHua Zhao \\ Engineering College, GANSU Agricultural University \\ Key Laboratory of Grassland Ecosystem Ministry of \\ Education, GANSU Agricultural University \\ Lanzhou, 730070, China \\ E-mail: zhaoch@gsau.edu.cn
}

\author{
Simon Blackmore \\ Engineering Department \\ Harpper Adams University \\ Edgmond, Shropshire, \\ TF10 8NB, Great British \\ E-mail: simon.blackmore@ @arper-adams.ac.uk
}

\author{
Michael Warbrick \\ Engineering Department \\ Harpper Adams University \\ Edgmond, Shropshire, \\ TF10 8NB, Great British \\ E-mail: mwarbrick@harper-adams.ac.uk
}

\author{
Sam Wane \\ Engineering Department \\ Harpper Adams University \\ Edgmond, Shropshire, \\ TF10 8NB, Great British \\ E-mail: swane@harper-adams.ac.uk
}

\begin{abstract}
R2100 sensor can provide an increased safety zone for Robot mower, it is necessary to use the advanced distance sensor that scans all kind of targets and receives data for the automatic control system and update the farm management information system. In this study, to determine the best height and view of the distance sensor. For use in modern precision agricultural automatic safety control system, a static and dynamic tests using a box , Cylinder, Cone and person as four target samples which were set at various points and lines were set at $0^{\circ}, 14^{\circ}, 44^{\circ}, 74^{\circ}$ and $8^{\circ}$ angle with the reference of the sensor at center. The distance sensor was set at $240 \mathrm{~mm}, 420 \mathrm{~mm}$ and $850 \mathrm{~mm}$ height, respectively. Tests and Statistical analysis of results showed that the accuracy of the new distance sensor mounted on Tomi's robot mower is up to $\mathbf{9 8 . 0 4 \%}$, and as far as the new safety system, it was set at $420 \mathrm{~mm}$ height that would be best location for scanning all kinds of obstacles, In order to evaluate the sensor's behavior, the practical field working conditions were imitated and the dynamic test showed the similar results with the static test.
\end{abstract}

Keywords- Distance sensor; Safety system; Target samples; Tests ; Analysis.

\section{INTRODUCTION}

As everyone knows that all of sensors have advantages and disadvantages, both of which should be considered before a commitment to a brand of sensing solution is chosen. Considering economical and practical functions as agricultural robot mower, knowledge of certain proximity sensor idiosyncrasies can help designers and users avoid pitfalls [1]. The project of development the safety system used for robot mower named Tomi that should be considered to ensure a successful sensing application are target detection capabilities, simplicities of mounting and setup, and the effects of the sensor's environmental surroundings whether they will be mechanical or electrical. Several applications of sensors were showed such as Lead frame position detection, Injection mold closure detection; Lathe control: Float detection for flow control, etc [2].

The study of OMD8000-R2100-R2-2V15 new type distance sensor first requires an understanding of the design fundamentals of the sensing technology. The new 2-dimensional multi-beam LED scanner uses tried-andtested PRT (Pulse Ranging Technology) and boasts a wide field of coverage. The eye-safe LED technology in the sensor allows it to be used by personnel in all working areas without posing a danger. The 11 emitter elements arranged side by side span a scanning range of 88 degrees such as Fig .1 [3], while the emitter LEDs set themselves apart through their large light spot. Measuring on a surface rather than on a point makes it easier to measure in homogeneous surfaces. A further highlight is the absence of any moving parts such as a motor or bearings, which makes the device less complex in its design and more resistant to mechanical stress[4]. The Scanners require an operating voltage of $24 \mathrm{~V} \mathrm{DC}$ to within $15 \%$ with a power consumption of $20 \mathrm{~W}$ plus the load on the three possible outputs OUT A, B (respectively max. $250 \mathrm{~mA}$ ) and OUT C (max. $100 \mathrm{~mA}$ ).The restart input can be allocated as restart or for changing field[5]. Power is supplied to the devices using a plug-in connection box with a high enclosure rating, while interface connection takes place through another connection box (RS 232) [6].Efficiency PRT ensures reliable and stable 2D measurement results, independent of the application environment. This makes the R2100 scanner a truly unique solution for a wide range of automation tasks.

R2100 sensor which

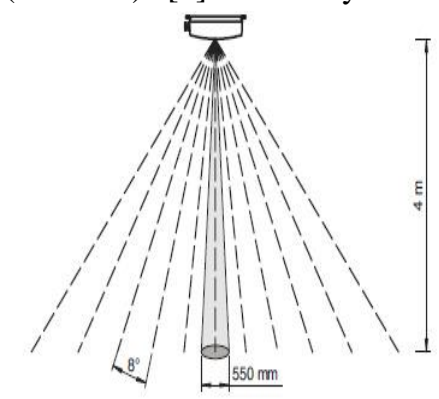

Figure 1.R2100 sensor Beam geometry 
used in Tomi's new safety system specifications may be described as the "detecting distance" to be the distance to a position at which the proximity sensor operates when measured from the reference position with the standard detectable target. Scanning distances for targets may not be able to be estimated from the manufacturer's data. These targets must be tested independently and measured so that the target's detection distance is determined for the sensor in question.

\section{MATERIALS AND METHOD}

In order to increase the Tomi' $\mathrm{S}$ new safety system reliability and ensure that the safety system is run using a separate system for robot mower, the Tomi' $s$ new safety system of central electronics board were built as showing Fig. 2 .

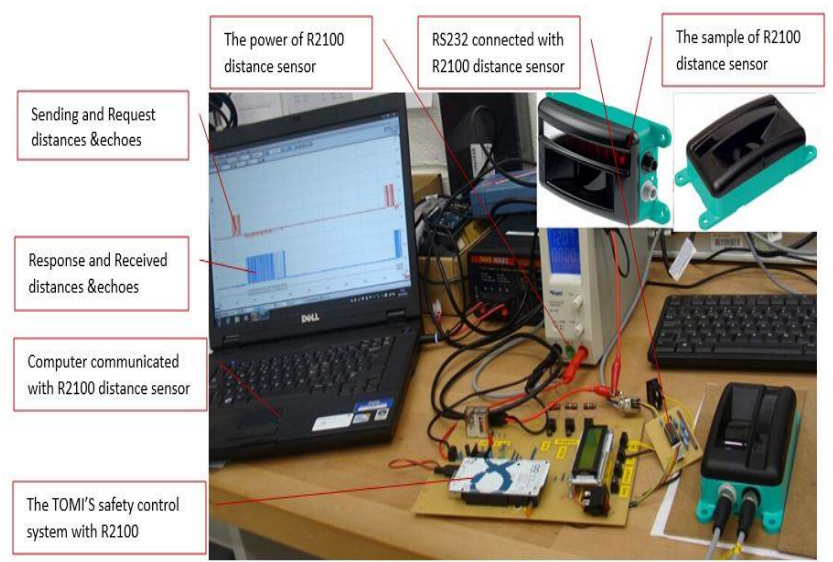

Figure 2. R2100 sensor static tests of the Tomi's new safety system central electronics broad (Source:Reach group, 2014)

\section{A. Tests data logger}

The R2100 sensor uses the following configuration for the serial ports : (a) The baud rate of serial port is set to be 19200 bps; and uses the 8 bits and 1Stop bits, the resolution of R2100 sensor is $1 \mathrm{~mm}$ and Interface type is RS 232; The R2100 evaluates targets using Pulse Ranging Technology(PRT) as the measuring method in two dimensions with Multi-Beam Scan-evaluating a 2D area using an array of wide-beam LED emitters. Combining this technology with PRT ensures reliable detection of any surface, regardless of shape or texture. And with no moving parts to break down or wear out over time, R2100 delivers extra durability, ruggedness, and measurement stability of distances in millimeters that is critical in mobile equipment applications.(b) Microprocessor (Philips P87LPC762BN, Philips, The Netherlands) with functions of Timer, once a pulse on the vibration sensor is detected, the microprocessor, via a mono stable stage, switches the circuit on for a pre-established time was used in static tests[7]. The FSK (frequency shift keying) modulation technique allows greater protection against electric noise compared to other types of RF modulations. (c) Arduino and Easy radio with functions of store program and transmission, receiver data for Serial Interface Board provides an easy to use, convenient communications adapt or for shifting between RS232 serial protocol and TTL logic levels in dynamitic tests[8,9]. The RF transmission module is a device based on TTL-RS232 logic (bit rate ranges from 9600 to $115200 \mathrm{bps}$ ), and data transmission is realised by the "store and forward" technique [10]: input data are stored in a buffer memory and transmitted at the end of reception. In the reception phase, the bytes are stored and transferred to the serial port only after the check sum validation. In case of transmission failure, all bytes received are rejected (in other words, the radio message must be completely transmitted). The maximum length of the transmissible data packet is 50 bytes. By sending "AT'" type commands the communication channel, serial speed, output transmission interval, power transmission and the identifying code can be selected by the user. To this end, for every triggering cycle, the same transmitter can be configured by using appropriate software; in this case, the receiver works like a transmitter and vice versa. When the transmitter is powered, the transmission module receives the microprocessor generated code. The code then passes through the FSK modulator device, the high frequency created is amplified then filtered by a band-pass filter to eliminate all harmonic waves. Finally, the signal can be transmitted witlessly. (d) Code generator, the microprocessor is generated via a time programmable radio frequency serial Hex code made up of 49 bytes numerical characters. This preset univocal code for each specific implement is generated by the micro process or triggered by the vibration sensor at a pre-defined frequency (commonly 1 code every $30 \mathrm{~s}$ ). scaning rate is $50 \mathrm{~s}-1(1$ scan $=11$ segments of a beam measurements).The electronic circuit of the transmitter can be divided into the following two parts:

\section{1) Sending and Request Distances}

Firstly, the current distances of R2100 sensor need request to be sent the frame which has five Bytes: $0 \times$ de; 0 $\times 01 ; 0 \times 05 ; 0 \times 59$ and $0 \times 83$ from number Byte 0 to Byte 4,respectly, this request should not be sent more often than every $20 \mathrm{~ms}$, and results reference only non-overlapping components when they are requested $50 \mathrm{~ms}$ or more apart.

2) Response and receiver Distances

There are 50 Bytes distances and echoes data from Byte 0 to Byte 49 may be received data, the first four Bytes which have $0 \times 01 ; 0 \times$ de; $0 \times 32 ; 0 \times 11$ from Byte 0 to Byte 3 are used as the sensor starting answers frame and the end Byte 49 are used as the end frame number, if a beam does not detect a target, the corresponding distance and echo values are reported as 0Xffff. In this paper, the program of Tomi's safety system was written about the distance values, the R2100 sensor and the Easy radio may response and communicate the distance values which need transfer the test data .Hexadecimal number need transfer into the decimalize number, and then analysis the data.

\section{B. Experimental method and Design}

Several methods and devices can be used for measuring distance such as pacing, Odometer, Taping or "chaining", Stadia; Optical range finder, Electronic distance measuring (EDM).One of the decisions that must be made when preparing to measure a distance is selecting the method or device to use. Considering practical circumstance, several methods of measuring distances were used in this project.

Before static and dynamic tests, the tests planning diagram should be designed and drawn such as Fig .3; Fig .4; Fig .5,using a box, cylinder, Cone and person as 
four target samples which were set at various points and lines were set at $0^{\circ}, 14^{\circ}, 44^{\circ}, 74^{\circ}$ and $88^{\circ}$ angle with the reference of the sensor at center, represent obstacle

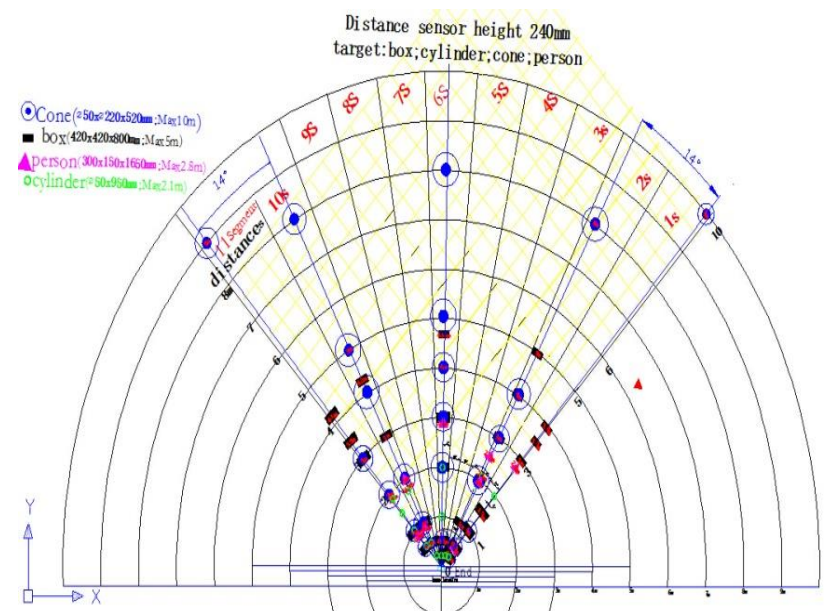

Figure 3.The static tests diagram of R2100 sensor was set at $240 \mathrm{~mm}$

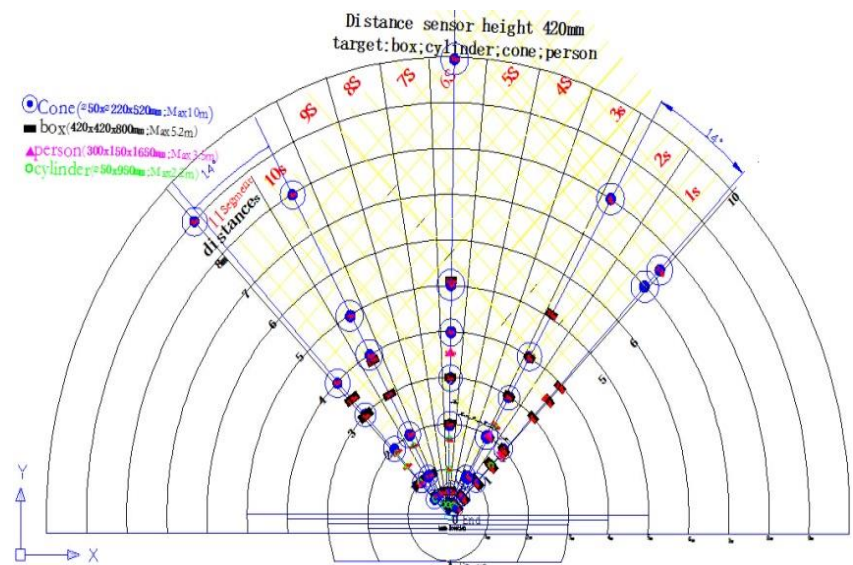

Figure 4.Thestatic tests diagram of R2100 sensor was set at $420 \mathrm{~mm}$

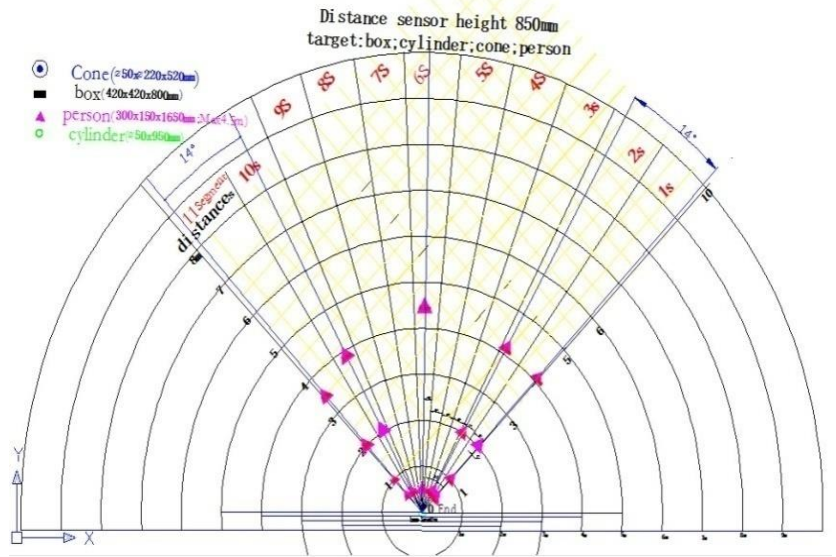

Figure 5.Static tests diagram of R2100 sensor was set at $850 \mathrm{~mm}$

vehicle, telegraph pole, pet and person models were presented to the new R2100 distance sensor. The distance sensor was set at $240 \mathrm{~mm}, 420 \mathrm{~mm}$ and $850 \mathrm{~mm}$ height, respectively, and the four targets were checked by static test and dynamic test, respectively. Tests were showed that dynamic which imitated the field test working average velocities about $1 \mathrm{~m} / \mathrm{s}$ is a more complex and a more realistic assessment of Tomi stability. The dynamic behavior of the Robot mower during cutting grass was determined by measuring the distances and angle, angular, and velocities.

\section{TEST AND RESULTS ANALYSIS}

\section{A. Test Plan}

Firstly, Test the overlap area: The target can be put on the center line at $4 \mathrm{~m}, 3 \mathrm{~m}, 2 \mathrm{~m}$ and $1 \mathrm{~m}$ dot marks distance, respectively, than check the safety system about Tomi, if Tomi is not stop, that means the two front distance sensors have not detected an obstacle need continue to check which one has problem and vice versa. Secondly, Check the Left and Right distance sensors operation: put the target at $4 \mathrm{~m}$ distance and the angle is $45^{\circ}$ with the horizontal line, if Tomi does not stop, the target can put at the right side of front $3 \mathrm{~m}, 2 \mathrm{~m}$ and $1 \mathrm{~m}$ as shown in the Fig .3, Fig .4, Fig .5, then continue to check the Left side with the similar method; Third, check the segments of the two distances. Target can be put at the Right side of front in $4 \mathrm{~m}, 3 \mathrm{~m}, 2 \mathrm{~m}, 1 \mathrm{~m}$ as following the map's dot mark, respectively, and check; whether the Left side of Front distance sensor is good or not good, following the Right side of Front distance sensor check's method. Lastly, more detailed information about the two front distance sensors can be gathered, and which segment is linked to the target, following the Fig .3,4,5 test diagram to divided each line of the four clearly lines into 11 segments which each segment is about 8 angular, than following the above steps to check the two front distance sensors.

In the dynamistic tests, the practical field working conditions were imitated and Tomi was run in a fixed velocities to the target samples which were set at various points and lines, then, following the static test plan and Fig . $3,4,5$ test diagram continue to do the tests.

\section{B. Test Results and Analysis}

Static test and dynamistic test results were showed by table 1 and table 2 .

TABLE I. THE MAXMIUM DISTANCE OF R2100 DISTANCE SENSOR STATIC TEST

\begin{tabular}{|c|c|c|c|c|}
\hline & \multirow[b]{2}{*}{ Serson hight } & \multirow{2}{*}{$\begin{array}{c}240 \\
M a \\
x \\
\text { distance } \\
\text { [m] }\end{array}$} & \multirow{2}{*}{$\begin{array}{c}420 \\
\\
\text { Max } \\
\text { distance } \\
\text { [m] }\end{array}$} & \multirow{2}{*}{$\begin{array}{c}850 \\
\text { Max } \\
\text { distance }[\mathrm{m}]\end{array}$} \\
\hline & & & & \\
\hline Cone & $\begin{array}{l}\varphi 50 \times \varphi 220 \times 520 \\
\mathrm{~mm}\end{array}$ & 10.00 & 10.00 & 0.00 \\
\hline $\mathrm{BOX}$ & $\begin{array}{l}420 \times 420 \times 800 \\
\mathrm{~mm}\end{array}$ & 5.00 & 5.20 & 0.00 \\
\hline person & $\begin{array}{l}\text { 300x150x1650 } \\
\text { mm }\end{array}$ & 2.80 & 3.50 & 4.50 \\
\hline Cylinder & $\varphi 50 \times 950 \mathrm{~mm}$ & 2.10 & 2.20 & 0.00 \\
\hline
\end{tabular}

Table1 showed that R2100 sensor setting on the height of $850 \mathrm{~mm}$ can be scanned $4.5 \mathrm{~mm}$ maximum distance to person target, but box, cylinder and cone targets can be scanned nothing, and setting on the height of $420 \mathrm{~mm}$ may be better than setting on the height of $240 \mathrm{~mm}$ because of the maximum distance is $3.5 \mathrm{~m}$ to person targe. 
Table 2 which was consisted of horizontal and vertical test implied that only limited data can be get because of the dynamic test is so complex, the limited data showed that the actual distance value is nearly similar to the theory distance value, but the accuracy tolerate of dynamic test is not better than the static test, dynamic test's targets are one box and one cone and the velocity of Tomi is range from $0.8 \mathrm{~m} / \mathrm{s}$ to $1.2 \mathrm{~m} / \mathrm{s}$.

From the static and dynamic test, the relationships between four targets and R2100 sensor in horizontal test were showed in table 3 , the box ,cone and cylinder targets were set at $0^{\circ}, 14^{\circ}, 44^{\circ}, 74^{\circ}$ and $88^{\circ}$ angle with the reference of the sensor at center, and every five regression equations showed the relationships between the target's actual distances value and the theory distance value to the R2100 sensor at the height $240,420 \mathrm{~mm}$,respectively. the accuracy tolerate and suitable height in vertical test also were analysis to person target at the height 240, 420, $850 \mathrm{~mm}$,respectively, it showed that the new sensor setting on height $420 \mathrm{~mm}$ is more accurate scanning person than the height $240, \quad 850 \mathrm{~mm}$.

TABLE II. THE DYNAMISTIC TEST OF R2100 DISTANCE SENSOR

\begin{tabular}{|c|c|c|c|c|c|c|c|c|c|c|c|c|c|c|}
\hline \multirow[t]{6}{*}{$\begin{array}{c}\text { Sensor } \\
\text { height }(\mathrm{mm})\end{array}$} & \multirow[t]{6}{*}{ Target } & Angle & $\begin{array}{c}\text { Segments } \\
\text { Distance [m] }\end{array}$ & 1 & 2 & 3 & 4 & 5 & 6 & 7 & 8 & 9 & 10 & 11 \\
\hline & & $0^{\circ}$ & 5.00 & 4539.13 & 5044.00 & 5044.00 & & & & & & & & \\
\hline & & $0^{\circ}$ & 3.00 & 2991.25 & & & & & & & & & & \\
\hline & & $0^{\circ}$ & 2.00 & 2130.00 & 2192.00 & & & & & & & & & \\
\hline & & $0^{\circ}$ & 1.30 & 1143.00 & 1097.33 & 1137.71 & 1394.78 & & & & & & & \\
\hline & & $14^{\circ}$ & 1.00 & 1153.00 & 1281.00 & 1288.00 & 1337.00 & & & & & & & \\
\hline \multirow[t]{4}{*}{240} & \multirow[t]{4}{*}{ cone } & $0^{\circ}$ & 9.00 & 9192.00 & & & & & & & & & & \\
\hline & & $14^{\circ}$ & 9.00 & & 9682.33 & & & & & & & & & \\
\hline & & $74^{\circ}$ & 9.00 & & & & & & & & & 9912.67 & & \\
\hline & & $88^{\circ}$ & 5.00 & & & & & & & & & & 5560.00 & 5461.00 \\
\hline \multirow[t]{2}{*}{420} & \multirow[t]{2}{*}{ cone } & $0^{\circ}$ & 8.00 & & 9096.00 & & & & & & & & & \\
\hline & & $88^{\circ}$ & 9.00 & & & & & & & & & & & 9528.50 \\
\hline \multirow[t]{9}{*}{850} & \multirow[t]{5}{*}{ cone } & $0^{\circ}$ & 10.00 & & 10424.00 & & & & & & & & & \\
\hline & & $0^{\circ}$ & 8.00 & & 8618.00 & & & & & & & & & \\
\hline & & $0^{\circ}$ & 4.50 & & 5636.00 & & & & & & & & & \\
\hline & & $0^{\circ}$ & 3.00 & & & 4024.00 & & & & & & & & \\
\hline & & $0^{\circ}$ & 1.00 & 1211.00 & 1259.00 & & & & & & & & & \\
\hline & \multirow[t]{4}{*}{ cone } & $44^{\circ}$ & 8.00 & & & & & & 8425.50 & & & & & \\
\hline & & $44^{\circ}$ & 6.00 & & & & & & 6666.00 & & & & & \\
\hline & & $44^{\circ}$ & 4.00 & & & & & & 4734.00 & & & & & \\
\hline & & $44^{\circ}$ & 4.00 & & & & & & 4497.00 & & & & & \\
\hline
\end{tabular}

TABLE III. THE CONCLUSION OF R2100 DISTANCE SENSOR TEST

\begin{tabular}{|c|c|c|c|c|c|c|c|}
\hline \multirow[b]{2}{*}{ Target } & \multirow{2}{*}{$\begin{array}{r}\text { Serson } \\
\text { hight }\end{array}$} & \multicolumn{2}{|c|}{240} & \multicolumn{2}{|c|}{420} & \multicolumn{2}{|c|}{850} \\
\hline & & Equation & $\begin{array}{l}\text { R square } \\
\text { value }\end{array}$ & Equation & $\begin{array}{l}\text { R square } \\
\text { value }\end{array}$ & Equation & $\begin{array}{c}R \\
\text { square } \\
\text { value }\end{array}$ \\
\hline \multirow{5}{*}{$\mathrm{BOX}$} & $0^{\circ}$ & $\mathrm{y} 1=5.672 \mathrm{X}^{0.782}$ & $\mathrm{R}^{2}=0.938$ & $\mathrm{y} 1=1.859 \mathrm{X}^{0.920}$ & $\mathrm{R}^{2}=0.999$ & & \\
\hline & $14^{\circ}$ & $\mathrm{y} 2=0.999 \mathrm{x}+23.82$ & $\mathrm{R}^{2}=0.999$ & $\mathrm{y} 2=1.002 \mathrm{x}+28.94$ & $\mathrm{R}^{2}=0.995$ & & \\
\hline & $44^{\circ}$ & $\mathrm{y} 3=0.987 \mathrm{x}+77.65$ & $\mathrm{R}^{2}=0.999$ & $\mathrm{y} 3=0.981 \mathrm{x}+102.4$ & $\mathrm{R}^{2}=0.999$ & & \\
\hline & $74^{\circ}$ & $\mathrm{y} 4=2.576 \mathrm{x}^{0.884}$ & $\mathrm{R}^{2}=0.994$ & $\mathrm{y} 4=1.768 \mathrm{x}^{0.928}$ & $\mathrm{R}^{2}=0.998$ & & \\
\hline & $88^{\circ}$ & $\mathrm{y} 5=0.992 \mathrm{x}+41.43$ & $\mathrm{R}^{2}=0.999$ & $\mathrm{y} 5=0.972 \mathrm{x}+64.97$ & $\mathrm{R}^{2}=0.999$ & & \\
\hline \multirow{5}{*}{ Cylinder } & $0^{\circ}$ & $\mathrm{y} 1=0.581 \mathrm{x}^{0.988}$ & $\mathrm{R}^{2}=0.975$ & $y 1=430.6 e^{0.001 x}$ & $\mathrm{R}^{2}=0.897$ & & \\
\hline & $14^{\circ}$ & $\mathrm{y} 2=1.062 \mathrm{x}-8.087$ & $\mathrm{R}^{2}=0.993$ & $\mathrm{y} 2=1.946 \mathrm{x}^{1.001}$ & $\mathrm{R}^{2}=0.986$ & & \\
\hline & $44^{\circ}$ & $\mathrm{y} 3=0.922 \mathrm{x}+179.2$ & $\mathrm{R}^{2}=0.998$ & $\mathrm{y} 3=1.813 \mathrm{x}+143.8$ & $\mathrm{R}^{2}=1$ & & \\
\hline & $74^{\circ}$ & $y 4=0.982 x^{1.014}$ & $\mathrm{R}^{2}=0.989$ & $\begin{array}{c}\mathrm{Y} 4=1.913 \mathrm{x}+24.9 \\
2\end{array}$ & $\mathrm{R}^{2}=1$ & & \\
\hline & $88^{\circ}$ & $y 5=0.936 x+45.26$ & $\mathrm{R}^{2}=0.996$ & $\mathrm{y} 5=4.493 \mathrm{x}^{0.853}$ & $\mathrm{R}^{2}=1$ & & \\
\hline \multirow{5}{*}{ Cone } & $0^{\circ}$ & $\mathrm{y} 1=1.248 \mathrm{x}^{0.959}$ & $\mathrm{R}^{2}=0.999$ & & $\mathrm{R}^{2}=0.999$ & & \\
\hline & $14^{\circ}$ & $\mathrm{y} 2=1.050 \mathrm{x}-28.83$ & $\mathrm{R}^{2}=0.998$ & & $\mathrm{R}^{2}=0.999$ & & \\
\hline & $44^{\circ}$ & $\mathrm{y} 3=1.017 \mathrm{x}+30.53$ & $\mathrm{R}^{2}=0.988$ & & $\mathrm{R}^{2}=0.871$ & & \\
\hline & $74^{\circ}$ & $\mathrm{y} 4=1.422 \mathrm{x}^{0.953}$ & $\mathrm{R}^{2}=0.999$ & & $\mathrm{R}^{2}=0.997$ & & \\
\hline & $88^{\circ}$ & $\mathrm{y} 5=0.975 \mathrm{x}-29.80$ & $\mathrm{R}^{2}=0.998$ & & $\mathrm{R}^{2}=1$ & & \\
\hline \multirow{5}{*}{ person } & $0^{\circ}$ & $\begin{array}{c}y 1=- \\
0.000 x^{2}+1.698 x+149.6\end{array}$ & $\mathrm{R}^{2}=0.666$ & $y 1=418.2 e^{0.000 x}$ & $\mathrm{R}^{2}=0.999$ & $\mathrm{y} 1=5.218 \mathrm{x}^{0.791}$ & $\mathrm{R}^{2}=0.987$ \\
\hline & $14^{\circ}$ & $\mathrm{y} 2=0.341 \mathrm{x}+1489$ & $\mathrm{R}^{2}=1$ & $y 2=2739 . e^{8 E-05 x}$ & $\mathrm{R}^{2}=1$ & $\mathrm{y} 2=0.988 \mathrm{x}+125.3$ & $\mathrm{R}^{2}=0.993$ \\
\hline & $44^{\circ}$ & $\mathrm{y} 3=1049 \cdot \ln (\mathrm{x})-5904$. & $\mathrm{R}^{2}=0.780$ & $\mathrm{y} 3=711.6 \mathrm{e}^{0.000 \mathrm{x}}$ & $\mathrm{R}^{2}=1$ & $\mathrm{y} 3=0.954 \mathrm{x}+342.8$ & $\mathrm{R}^{2}=0.997$ \\
\hline & $74^{\circ}$ & $\mathrm{y} 4=578.2 \mathrm{e}^{0.000 \mathrm{x}}$ & $\mathrm{R}^{2}=0.995$ & $\mathrm{y} 4=0.445 \mathrm{x}+1090$ & $\mathrm{R}^{2}=1$ & $\mathrm{y} 4=6.163 \mathrm{x}^{0.777}$ & $\mathrm{R}^{2}=0.972$ \\
\hline & $88^{\circ}$ & $\mathrm{y} 1=1.859 \mathrm{X} 0.922$ & $\mathrm{R}^{2}=0.995$ & $\mathrm{y} 5=0.388 \mathrm{x}+551.9$ & $\mathrm{R}^{2}=0.995$ & $\mathrm{y} 5=0.985 \mathrm{x}+106.3$ & $\mathrm{R}^{2}=0.999$ \\
\hline Average & Total & 0.9804 & 0.9649 & & 0.9867 & & 0.9896 \\
\hline
\end{tabular}




\section{SUMMARY}

From the result of table 3, the static tests and dynamic tests showed that: the distance sensor of R2100 is reliable and accurate. the accuracy of R2100 setting at height $240 \mathrm{~mm}$ is up to $96.49 \%$, at height $420 \mathrm{~mm}$ is up to $98.67 \%$, at height $850 \mathrm{~mm}$ is up to $98.96 \%$, but in this three height level, it can be only detected the person target when setting at height of $850 \mathrm{~mm}$. as far as Tomi's new safety system, it was set at $420 \mathrm{~mm}$ height that would be best location for scanning all kinds of obstacles. Tests and Statistical analysis of results showed that the average accuracy tolerate of R2100 sensor mounted on Tomi's robot mower is up to $98.04 \%$, and In order to evaluate the distance sensor's behavior, the field working conditions were imitated and the dynamic test showed the similar results with the static test.

The results suggested that the R2100 new sensor could potentially be helpful for detecting the distance of targets. Further studies are suggested to address whether different shape and size are better related to the state of scanning target."size of detectable object versus detecting distance."

\section{ACKNOWLEDGMENT}

The paper would been funded: Special Fund for Agroscientific Research in the Public Interest (Project No. 201203024); 2012 Outstanding Youth Foundation in Gansu province (Project No.2012GS05590), and the Project of Gansu Agricultural Scientific and Technological Innovation (Project No.GNCX-2013-39).and the First Fuxi's outstanding talent candidates project in Gansu Agricultural University; The author would like to thank for professor Simon Blackmore and all of the staffs in Engineering Department, The project has been carried out at the Agricultural Engineering innovative Centre in HARPER ADAMS UNIVERSITY in UK. The author was gratefully appreciated acknowledge financial support from the CHINA SCHOLARSHIP COUNCIL (CAC).

\section{REFERENCES}

[1] Nikkila,R., Seilonen,I., Koskinen, K. "Software architecture formanagement information systems in precision agriculture". Comput. Electron.Agric.70, 2010.pp.328-336.

[2] Omron Electronics LLC, Safety Product Marketing Manager, Your Inductive Proximity Sensor Strategy, TheTechnology, Specification, and Implementation of Authored by Reno Suffi, 2013.

[3] Information on http://www.PEPPERL+FUCHS. products introduce, 2014.

[4] E.J. Van Henten D. Goense C.Lokhorst. Precision agriculture'09. Wageningen Academic Publishers. Papers presented at the 7 th European Conference on Precision Agriculture Wageningen, the Netherlands 6-8 ,July 2009.

[5] Li, Z., Wang, N., Hong, T., 2010. Radio path-loss modeling for a $2.4 \mathrm{GHz}$ in-field wireless sensor network. Trans. ASABE53(2),615-624.

[6] Miles Metcalfe, James Meadows, Glen Ebsary and James Chapman, "DEMETER" Autonomous Precision Seed Planting Robot," May. 2014, unpublished.

[7] Polulu, 2014. Products. [On-Line] Available from: http://www.pololu.com/ [Accessed Juiy2014].

[8] Dorhout R and D,2013. Prospero; Robot Farmer. [On-line] Available from:http://dorhoutrd.com/prospero_robot_farmer [Accessed 10 April 2014]

[9] Oksanen, T., 2013. Accuracy and performance experiences of four wheel steered autonomous agricultural tractor in sowing operation. 9th International Conference on Field and Service Robotics, 9-11 December.pp. 1-14.

[10] Voulodimos, A.S., Patrikakis, C.Z., Sideridis, A.B., Ntafis, V.A., Xylouri, E.M., 2010. Acomplete farm management system based on animal identification usingRFID technology. Comput.Electron. Agric.70, 380-388. 